\title{
Assessment of the Level of Pre-School Childrens' Motor Skills
}

\author{
PhD. Ardian Shingjergji \\ EU "Aleksandër Xhuvani, Faculty of Educational Sciences \\ ardianshingjergji@gmail.com
}

\section{Doi:10.5901/ajis.2013.v2n11p174}

\begin{abstract}
The synthesis of what the diverse authors' viewpoints uphold regarding the pre-school children's motor skills is that they are developed in the course of their age and maturity. Growing-up and development on one side, as well as factors suchlike the environment, exposure and directions, play a determinative role to this regard. It is the task of the pre-school specialists, managers and teachers to secure the systematic continuity of the ongoing programmes offered to enhance the development of the motor skills. Relying on the close understanding of the problems encountered in the Albanian reality, regarding the psychomotor education of the pre-school children, it is regrettably noticed that the development of the motor skills in the preschool institutions, despite interventions and improvements made, still continues to be under the level of the contemporary experience. This results due to the fact that yet there isn't a clear perception of the level of the psychomotor skills development, estimated by tests. Relevantly, the goal of this study is the measurement of the motor skills level in age-groups 4-6 years olds as well as providing a simple functional model for their assessment, based on the developed countries' standards and experiences. Study methods include research, observation, surveying, testing, the statistical and computer processing, analyses and comparisons. This scale of study as well as the results deriving from it will serve to the pre-school teachers, directors of the pre-school institutions as well as students preparing as forthcoming teachers in the Faculty of Education Sciences.
\end{abstract}

Keywords: motor skills development, 4-6 year-old age groups, measurement, assessment.

\section{Introduction}

The thesis upheld by many scholars who compare humans' development, from the day they come to life and on, with a ten-storeyed building whose first eight floors are built within the initial six years is very well-known. In terms of the physical education as a whole and specifically the psychomotor education, a relative retardation has been detected in the pre-school age-group children, a reality which has risen the interest of many scholars and specialists of the field. The synthesis of the most advanced viewpoints and opinions to this regard suggest the deliberate organization and progress towards enriching the pre- school children's motor experiences. The issues related with guided development, or the optimal acceleration of the motor experiences for this age-group children has been considered, in addition to other aspects, (health, physical development), as an important social factor impacting the formation of their personalities positively as well as promoting tendencies to come closer to diverse sportive disciplines so revealing their talents and gifts as required by contemporary developments.

The observations and investigations accomplished by us have revealed that the development level of the children motor skills at our pre-school institutions results to be relatively low as compared to the developed countries standards. Basing on a closer investigation of the problems the actual pre-school children psychomotor education presents, this study intends to measure the level of the motor resultants and to present a simple and functional assessment model.

\section{Tests for Assessing Motor Skills}

So far these skills have not been measured or assessed by means of basic texts determined to reach this aim. Basing on this fact as well as on similar tests or the adapted and applied tests by other authors such as Lam (1990), Sigmundson, Rostoft (2003), a series of tests have been selected, having pre-determined criteria suchlike the proper age, as well being easily acquired and understood both by pre-school students and by teachers. The selected and applied tests were the following:

1. The speed test - running $30 \mathrm{~m}$.

2. The horizontal jump for distance test. 
3. The strength test - throwing a 400 gram filled ball.

4. The static equilibrium test - standing on one leg.

5. The dynamic equilibrium test - walking along a straight line.

6. The motor coordination test - jumping on both legs on some rings lying on the floor.

7. The hurdles jumping test.

\subsection{Methodical description of the applied tests.}

- The speed test (running 30m). Children start running from the start line once the visional signal has been given, going on a straight line all along the $30 \mathrm{~m}$ distance. The test is repeated twice and the best timing achieved is recorded.

- The horizontal jump for distance test. Children position their feet on the jumping line, with their legs slightly bended at the knees and supported by their arms do the horizontal jumping. The score is given in centimeters, the test is repeated twice, and the farthest jumping distance achieved is recorded, including faults, (line treading) which are calculated into children's achieved scores.

- The strength test, (throwing a 400 gram ball with both hands over the head). Children position their feet on the throwing line keeping the ball with both hands over the head and being supported by the force of their arms they try to throw the ball as far as possible. The test is repeated twice and the best score achieved, (measured in $\mathrm{cm}$ ) is recorded.

- The static equilibrium test, (standing on one leg). Children are free to choose the leg they will stand on and stand on it as long as they can while not touching the floor with the other lifted leg. The test is repeated twice, timing is kept in seconds.

- The dynamic equilibrium test, (walking along a straight $6 \mathrm{~cm}$ long and $3 \mathrm{~cm}$ wide line or strap). The test is repeated twice, and faults, (treading off lines) are calculated as penalties.

- The motor coordination test, (jumping on both legs on rings placed on the floor). Children jump on six rings placed zigzag on the floor, firstly ahead and then backwards. The test is repeated twice and the best timing achieved is recorded. Faults, suchlike jumping off rings or missing the determined jumping directions are calculated as penalties.

- The hurdles jumping test (jumping hurdles). Children starting from the start line, jump over the two $20 \mathrm{~cm}$-high hurdles, pass under a $60 \mathrm{~cm}$ hurdle, run along a winding track through three vertical hurdles, jump over the 45 x $50 \times 100 \mathrm{~cm}$ box, and keep running till the end of the determined distance $(9-10 \mathrm{~m})$ The test is repeated twice and the best score is recorded in seconds.

\section{The Application Procedure}

The group participating in the study was comprised of the study author, the director of the pilot kindergarten as well as the supporting group consisting of the teachers of the kindergartens selected for the study and the students of the Faculty of the Educational Sciences, the pre-school department, at the Elbasan University (EU) "Aleksander Xhuvani".

The study's geographical extension included the Elbasan, Librazhd, Gramsh, Lushnje and Berat districts and was applied in two stages: the precursory stage and the experimental stage.

The first stage was perceived as a phase for the organization of the work, to distribute the questionnaires to the kindergarten directors as well as to the parents' communities to be followed by the training sessions provided to the participants about the distribution procedures and the ways to obtain the information needed.

The data collected were subjected to the statistical computing processions and served to further discussions, comparisons and scientific analyses, relevant to the study's intentions. The analyses of the canvass' results brought forth the following conclusions:

The obtained data testified that teachers and parents have a low level of awareness regarding the psychomotor education and the psychomotricity in general. This is because it is a relatively new field of study and there is little awareness of it in our country. The data obtained from the pilot kindergarten show that it makes up exclusion to this regard, because of financial support and the training seminars provided repeatedly.

In the Education Faculty which prepares pre-school teachers, the subject of the psychomotor education is a new subject; the knowledge has been given singly, not integrated into the other fields of child's development. 
The canvass results made us draw the conclusion that, actually, a simple and functional model to assess the preschool children's motor skills is needed.

The second stage, the experimental one, involved 520 children of 4-6 year-old age group in 10 pre-school institutions in the aforementioned districts.

Tests were realized during the psychomotor education included in the curricula, during a one-month period April 2011, (a time period which coincides with the students' educational and pedagogical practices).

\section{Results and Discourses}

The scores achieved from testing the children's psychomotor skills have been presented in the following chart:

Chart. No.1: The scores achieved from testing the children's psychomotor skills

\begin{tabular}{|c|c|c|c|c|c|c|c|}
\hline \multirow[b]{2}{*}{$\begin{array}{l}\text { Age groups } \\
(\mathrm{n})\end{array}$} & \multicolumn{7}{|c|}{ Applied Tests } \\
\hline & $\begin{array}{c}1 \\
\text { Running } \\
30 \mathrm{~m} \\
(\mathrm{sec})\end{array}$ & \begin{tabular}{|c|}
2 \\
The horizontal \\
jump for distance \\
test $(\mathrm{cm})$
\end{tabular} & $\begin{array}{c}3 \\
\text { Throwing the } 400 \\
\text { gram } \\
\text { Ball }(\mathrm{cm})\end{array}$ & $\begin{array}{c}4 \\
\text { Static } \\
\text { equilibrium } \\
\text { (sec) }\end{array}$ & $\begin{array}{c}5 \\
\text { Dynamic equilibrium } \\
\text { (no. of faults) }\end{array}$ & $\begin{array}{c}6 \\
\text { Motoric } \\
\text { Coordination } \\
(\mathrm{sec})\end{array}$ & $\begin{array}{c}7 \\
\text { Hurdles } \\
\text { jumping (sec) }\end{array}$ \\
\hline \begin{tabular}{|l|} 
Age: 4 yrs old \\
$(162)$ \\
Boys (84) \\
Girls (78) \\
Probability \\
\end{tabular} & $\begin{array}{c}9.3 \\
(0.13)^{1} \\
9.2 \\
9.4 \\
0.1 \\
\end{array}$ & $\begin{array}{c}49.6 \\
(19.6) \\
50.8 \\
48.5 \\
0.06 \\
\end{array}$ & $\begin{array}{c}212 \\
(51.8) \\
220 \\
205 \\
0.02 \\
\end{array}$ & $\begin{array}{c}30.2 \\
(17.6) \\
28.1 \\
32.3 \\
0.12 \\
\end{array}$ & $\begin{array}{c}2.3 \\
(1.6) \\
2.3 \\
2.3 \\
0.94 \\
\end{array}$ & $\begin{array}{c}14.4 \\
(3.05) \\
14.3 \\
14.5 \\
0.42 \\
\end{array}$ & $\begin{array}{l}11.2 \\
(1.54) \\
10.5 \\
11.9\end{array}$ \\
\hline $\begin{array}{l}\text { Age } 5 \text { yrs old } \\
(186) \\
\text { Boys }(114) \\
\text { Girls (72) } \\
\text { Probability }\end{array}$ & $\begin{array}{c}8.2 \\
(0.15) \\
8.1 \\
8.4 \\
0.11\end{array}$ & $\begin{array}{c}85.7 \\
(25.8) \\
87.5 \\
84 \\
0.04\end{array}$ & $\begin{array}{c}265 \\
(59.6) \\
285 \\
245 \\
0.04\end{array}$ & $\begin{array}{c}45.6 \\
(11.8) \\
45.1 \\
46.2 \\
0.79\end{array}$ & $\begin{array}{c}1.6 \\
(0.96) \\
1.6 \\
1.6 \\
0.88\end{array}$ & $\begin{array}{c}11.2 \\
(3.01) \\
11.1 \\
11.4 \\
0.32\end{array}$ & $\begin{array}{c}8.5 \\
(1.42) \\
8.3 \\
8.7 \\
0.14\end{array}$ \\
\hline \begin{tabular}{|l|} 
Age 6 yrs old \\
$(172)$ \\
Boys $(102)$ \\
Girls (70) \\
Probability ${ }^{2}$
\end{tabular} & $\begin{array}{c}7.4 \\
(0.20) \\
7.3 \\
7.5 \\
0.12\end{array}$ & $\begin{array}{c}105.8 \\
(26.5) \\
107.2 \\
104.5 \\
0.11\end{array}$ & $\begin{array}{c}366 \\
(75.1) \\
387 \\
345 \\
0.02\end{array}$ & $\begin{array}{c}53.9 \\
(19.7) \\
51.3 \\
56.5 \\
0.14\end{array}$ & $\begin{array}{c}0.53 \\
(0.70) \\
0.58 \\
0.49 \\
0.71\end{array}$ & $\begin{array}{c}8.3 \\
(1.53) \\
8.1 \\
8.5 \\
0.16\end{array}$ & $\begin{array}{c}7.5 \\
(0.91) \\
7.4 \\
7.6 \\
0.04\end{array}$ \\
\hline
\end{tabular}

Chart. No. 2: The scores achieved from testing the children's psychomotor skills

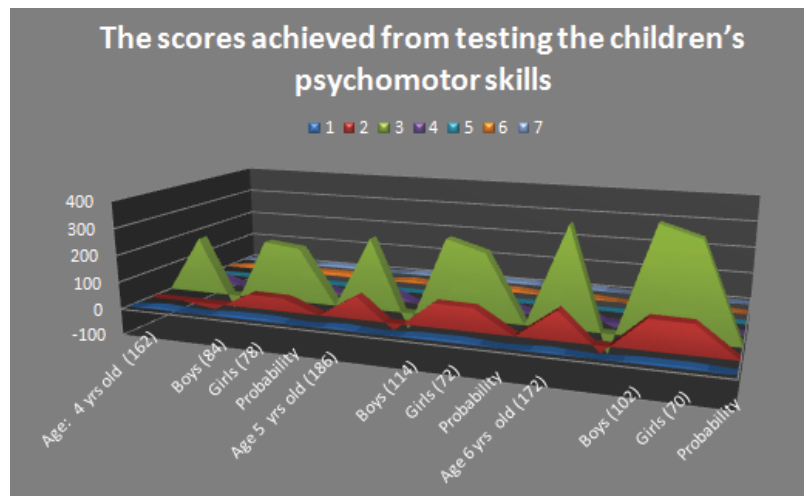

${ }^{1}$ Data in brackets present standard deviation.

2 Probability expresses gender variables for each age-group. 
Data were subjected to computerized statistical processing by means of which the main statistical indicators were computed for each single variable. The even distribution of the data was computed by using the Kolmogorov-Smirnov method. Distinctive analyses were used to highlight the data of the age-group and gender variables while tests were used considering the differences in the results by age and gender.

Results showed that:

The speed indicator resulted to have very slight differences between the age and gender. Similar results were also for the strength indicator whereas for the horizontal jump for distance indicator the results showed that the differences between the age and gender within the same age group are insignificant. By comparing these results with the assessment of the 4-6 age group children motor skills by foreign authors such as Meinel (1960), Blume (1966), Popov (1971), the differences are considerable.

Chart. No.3: Comparative form of the motor skills assessment results by authors Meinel, Schnabel (1984).

\begin{tabular}{|c|c|c|c|}
\hline Indicators & Age 3-4 yrs old & Age 5-6 yrs old & Growth \\
\hline -Running $40 \mathrm{~m}$ & $13.6 \mathrm{sec}$ & $9.8 \mathrm{sec}$ & $138 \%$ \\
\hline $\begin{array}{l}\text { The horizontal jump for } \\
\text { distance }\end{array}$ & $47.8 \mathrm{~cm}$ & $116.7 \mathrm{~cm}$ & $243 \%$ \\
\hline $\begin{array}{l}\text { Throwing the ball over } \\
\text { head }\end{array}$ & $3.79 \mathrm{~m}$ & $\begin{array}{l}12.90 \mathrm{~m} \\
\text { Popov, } 1971\end{array}$ & $340 \%$ \\
\hline $\begin{array}{l}\text { Throwing the ball over } \\
\text { head (in terms of quality) }\end{array}$ & $\begin{array}{l}\text { Without body engagement from the } \\
\text { frontal position. }\end{array}$ & $\begin{array}{l}\text { Impetus throwing, crossed steps or } \\
\text { intermediate jumps. }\end{array}$ & $\begin{array}{l}\text { Meinel,1960. } \\
\text { Blume,1966. }\end{array}$ \\
\hline Catching the ball in the air & $\begin{array}{l}\text { Without anticedance,only to the chest } \\
\text { height, if passing is correctly but they } \\
\text { still can't cope to combine both the } \\
\text { capture and jumping. }\end{array}$ & $\begin{array}{l}\text { Free capture from chest to head with the } \\
\text { expected anticedance and as combination } \\
\text { between the capture and release } \\
\text { movements. }\end{array}$ & $\begin{array}{l}\text { Dobler, } 1957 . \\
\text { Schreiter, } 1963 .\end{array}$ \\
\hline Jumping & $\begin{array}{l}\text { The horizontal jump for distance, } \\
\text { jumping while crawling. Jumping over } \\
\text { the objects placed on the ground } \\
\text { suchlike: rope, sticks, rings, } \\
\text { etc. }\end{array}$ & $\begin{array}{l}\text { Distance and height jumping (height about } \\
50 \mathrm{~cm} \text { ), repeated jumpings, combination of } \\
\text { running and jumping, jumping games, etc. }\end{array}$ & $\begin{array}{l}\text { Winter, } 1961 . \\
\text { K. Lewin, } 1973 .\end{array}$ \\
\hline
\end{tabular}

While referring to the foreign authors, such as Hands, Larkin (1997), Lam et al. (2003), our study results showed that for this age-group boys are faster than girls.

The speed skill's results showed that there are slight differences between genders, $(0.2-0.3 \mathrm{sec}$.) and between age-groups (1.1-1.2 sec.). Comparing these with the results of the comparative formatting it results that the 4-5 agegroups are represented by the same indicators: (the difference is $0.3-0.4 \mathrm{sec}$.).The variables shown become more evident for the 5-6 age groups (1.4-2.4 sec.). These interesting data prove the aforementioned opinion that both the skills' growth and development, beyond the line of natural development, should be supported by leading it with respective instructions and curricula.

Results achieved in the horizontal jumping for distance test showed that differences within the same age-group are insignificant. However, when compared with comparative format indicators by Meinel and Blume, they are more visible $(21.7-30 \mathrm{~cm})$.

Similar results were achieved in the strength skills test. So for example, results between two genders for the 4-5 age group children are approximately similar, (difference among them sways among 10-15 cm). Differences are especially visible for the 5-6 age groups, $(40-50 \mathrm{~cm})$. When compared with the measurements by the up-mentioned authors there is more obvious difference in these results. $(94-114 \mathrm{~cm})$.

The static equilibrium indicator's results are equal with the those of the other authors such as Sigmundson, Rostoft (2003), who, in their studies found significant variables between the two genders with girls reaching higher levels than boys, (differences between the genders of the same age group sway into the following limits: (4.2-5.2 sec).

The dynamic equilibrium indicator results show that there are similarities and there are not any essential variables between the genders, showing that these abilities are developed with the age. Similar results have been achieved in the 
studies by authors such as Morris et al. (1982), who did not find obvious statistical variables between the genders for the children of 3-6 age groups regarding the dynamic equilibrium skills.

Results related to the motor coordination skills showed insignificant variables between genders of the same age, (0.2-0.4 sec), while showing variables between age groups. (2.9-3.2 sec).

The jumping hurdles test differences in the results between the two genders of the same age group were small and in the boys' favor (0.4-1.4 sec.), whereas there were variables between age-groups. Thus, for example, differences in results were bigger between the 4-5 yrs old $(2.3-2.7 \mathrm{sec})$ and smaller between the 5-6 yrs old. (0.9-1.1 sec.).

In conclusion these results showed that the pre-school children motor skills are gradually developed and improved whilst their age advances, while considering the fact that the specific variables between the age and gender are visible. Regarding the child's development, results showed that up to 5 years of age there is normal development while there is evidence of the fast and impetus development after this age. In this regard, many obvious variables were noticed between the two genders and those between age-groups were significant.

\section{Conclusions and Recommendations}

1. In our study we strived to bring forth a simple and functional measurement and assessment model for the preschool children motor skills. Since these tests cover a considerable part of the children's motor activities, we modestly offer this model to the pre-school institutions directors and teachers, the pre-school education students, the parents' communities, to the specialists of the psychomotor education, the regional educational directories and other state cogs and the psychomotor education specialists so that they present it as a development and improvement standard for these skills according to the respective age groups.

2. The study showed that the tests selected by us were fully understood and administered by the groups of interests involved into the study. This is another fact reinforcing our belief that these tests can, therefore, serve as a model for the assessment of the pre-school children motor skills.

3. These results, which gave a clear reflection of the development level of those children's general motor skills, suggest the need to evolve suitable curricula and instructions for their application in the future. In this aspect, it remains as a task for the pre-school specialists, directors and teachers to provide their assistance for the development of those skills, aiming to improve the children's activities structure and quality, so they have a more active life and enjoy all the benefits it renders. .

4. A study of this kind and the results deriving from it, make up solely a single step in the long way of the journey and explorations in this very important field, which still remains insufficiently known and explored by us. This is what we intended and wish to assert and conduct via our study in this field, in which whoever can give his/her own contribution for its further enrichment and evolvement.

\section{References}

Hands, B. , \& Larkin, D. (1997). "Gender bias in measurement of movement'. The ACHPER Healthy, Lifestyles Journal, p. 44(1), 12-16.

Sigmundson, H. \& Rostoft, M. S. (2003). "Motor development: Exploring the motor competence of 4-year old Norwegian children". Scandinavian Journal of Educational Research, p. 47(4), 451-459.

Reference to a book:

Meinel, K. , \& Schnabel, G. (et al.). (1984). "Teoria del movimento". Societa Stampa Sportiva, Roma.

Reference to a chapter in an edited book:

Kamani, P. , \& Mato, E. (2004). "Achievement standards in pre-school education". Pre-school education, 6. ISP. Tiranë, p. 5, 18-19, 20, 37-38, 61-62.

Lam, H. M.Y. , Ip, M. H. , Lui, P. K. , \& Kong, M. K. (2003). "How teachers can asses kindergarden children's motor performance in Hong Kong". Early Child Development and Care, p. 173(1), 109-118.

Morris, A. M. , Williams, J. M. , Atwater, A. \& Wilmore, J. H. (1982) "Age and sex differences in motor performance of 3 through 6 year old children". Research Quarterly for Exercise and Sport, p.53, 214-221. 